\title{
Quality of Life among the Elderly at Rumah Seri Kenangan, Cheras, Malaysia
}

\author{
Mag Wencellas' ${ }^{1}$, Rugayah Hashim² \\ ${ }^{1}$ Faculty of Administrative Science \& Policy Studies, \\ Universiti Teknologi MARA, Shah Alam 40450, Malaysia \\ 2 Research \& Innovation Unit, \\ Universiti Teknologi MARA Cawangan Selangor, Puncak Alam 42300, Malaysia \\ mag.wencell@gmail.com, guy73106@yahoo.com \\ Tel: +603 32584333
}

\begin{abstract}
The research objectives were to determine the relationships between age, education level, previous employment, and marital status towards the quality of life among the elderly at Rumah Seri Kenangan, Cheras. The study employed a quantitative research approach through the adoption of the Ferrans conceptual model for quality of life. The consensus sampling technique evoked a sample size of $n=145$. The analyses obtained from this study revealed that there were no significant relationships between the first three independent variables to their quality of life except for marital status; the quality of life is better if there is companionship among the elderly.
\end{abstract}

Keywords: Elderly; Quality of Life; Social environment; Demography

eISSN: 2398-4287 @ 2019. The Authors. Published for AMER ABRA cE-Bs by e-International Publishing House, Ltd., UK. This is an open access article under the CC BYNC-ND license (http://creativecommons.org/licenses/by-nc-nd/4.0). Peer-review under responsibility of AMER (Association of Malaysian Environment-Behaviour Researchers), ABRA (Association of Behavioural Researchers on Asians) and cE-Bs (Centre for Environment-Behaviour Studies), Faculty of Architecture, Planning \& Surveying, Universiti Teknologi MARA, Malaysia. DOI: https://doi.org/10.21834/e-bpj.v4i12.1752

\subsection{Introduction}

Most individuals around the world are living longer, as pointed out by the World Health Organization (2018). The aging world population was estimated at 900 million, and it is expected that the world's population aged 60 years and above will increase to two billion by the year 2050. Furthermore, it also anticipated that China would have the greatest number of the aging population by having 120 million elderly citizens by 2050. Besides, the aging population around the world except China will be amounting to 434 million by 2050. Hence, the WHO (2018) report anticipated that by $2050,80 \%$ of the aging population would be predominantly seen between developing countries (countries ranked with low to the middle-income nation).

On the other hand, an upsurge in the aging population from high-income countries like Japan, where $30 \%$ of its population consisted of older people aged 60 years and above (World Health Organization, 2018). Nevertheless, the increasing trend of the aging population is also seen in low and middle-income countries like Malaysia. Among the significant changes and challenges that these small and middle-income countries faced were in the provision of good healthcare in their social systems. As claimed by the United States Department of Health and Human Services (2016), an increase in life expectancy can bring benefits to an entire society, and not just the elderly and their families. For instance, the elderly who are living longer will have the opportunity to further their education, discover a new profession, or even continue to do the things that they are passionate about, which they have neglected for a long time (Kahlbaugh \& Huffman, 2017).

\subsection{Background}

elSSN: 2398-4287 @ 2019. The Authors. Published for AMER ABRA cE-Bs by e-International Publishing House, Ltd., UK. This is an open access article under the CC BYNC-ND license (http://creativecommons.org/licenses/by-nc-nd/4.0). Peer-review under responsibility of AMER (Association of Malaysian Environment-Behaviour Researchers), ABRA (Association of Behavioural Researchers on Asians) and cE-Bs (Centre for Environment-Behaviour Studies), Faculty of Architecture, Planning \& Surveying, Universiti Teknologi MARA, Malaysia. DOI: https://doi.org/10.21834/e-bpj.v4i12.1752 
Healthy living, wellness, and sound quality of life have been the root causes of people living longer than anticipated. Several factors from the literature reviewed have evidenced that the elderly can still contribute in various ways to families as well as the community. These contributions and opportunities, however, are primarily influenced by one crucial factor, which is health (Organization, 2018). As people age, they struggle to keep themselves healthy. The evolution of life affects the cells of their bodies, thus, exposing them to the risk of chronic diseases and health problems. For instance, the National Council on Aging (2018), in the United States, pointed out that chronic diseases such as cancer, heart problem, excessive level of glucose in the blood, stroke as well as dementia are among the main fatality factors for senior citizens. Other factors that were commonly found to be influenced by healthy aging were the physical state of the golden agers and their social environment. As pointed out by the World Health Organization (2018), the socio-demographic determinants, namely ethnicity, gender, and socioeconomic status, also exert influence on healthy aging in the senior citizen's population. With that explained, this study comes at an opportune time in determining the relationships between age, education level, previous employment, and marital status towards the quality of life among the elderly at Rumah Seri Kenangan, Cheras.

\subsection{Literature Review}

A healthy aging society has become a national priority on public health with infrastructure design (Cellucci \& Di Sivo, 2020). The same applies to Malaysia. With a forward elderly population in which those who are 60 years and above, it is predicted that Malaysia's aging society will reach 13.6 percent by 2030 (Statistics-Malaysia, 2019). The improvement in the healthcare sector has brought a positive impact on the Malaysian population resulting in a longer life span for the citizens. For instance, the development of sanitation, food security, and security from infectious diseases through scheduled vaccinations have increased the lifespan population in Malaysia. As indicated by the Department of Statistics (2019), Malaysians aged 60 years and above are reaching 9.5 percent of the population. This means that by $2045,14 \%$ of Malaysians will be part of the "aged nation" segment (Tobi, Fathi, \& Amaratunga, 2017). On the other hand, while longer life expectancy is positively perceived, it also develops new challenges for the country where the senior citizens will need better facilities according to their privileges.

Nevertheless, successful aging requires the active involvement of society (Fung, 2020). For instance, Fung (2020), stated that resilience at both the individual and community level is important for the elderly to enjoy a good quality of life. That said, there are also limitations to successful aging, such as creating the nursing home care, professional human resource, and providing a community which is friendly towards the geriatric population.

The improvement to the quality of life in older people in most countries of the world has been positive, for example, Japan's coaching program (Ohashi \& Katsura, 2019). One such positivity is the increased lifespan among the Japanese (ibid). On the other end of the spectrum, good healthcare for the aging population has shown an inverse relationship with the population control. The Japanese population has decreased significantly, as evidenced by the decline in the fertility rate (ibid. The phenomenon of these issues is known as "Double Graying" or "Population Graying" (Nelson, 2016).

There are many interpretations of the standard level of expectations for a decent life or popularly known as quality of life (QOL) model (Nilvarangkul et al., 2010). One such model is the "Rubik's Cube" of well-being, which illustrated the concepts that whenever a change takes place in one dimension, other dimensions will also be affected (Nilvarangkul, McCann, Rungreangkulkij, \& Wongprom, 2010). Hence, for the study, the theoretical underpinnings proposed from the QoL model focused on these dimensions, namely, physical, emotional, social, intellectual, spiritual, and environmental. These dimensions were then correlated to the demographic variables, as advocated by Ferran's model (Ferrans, 1996).

The first dimension, which is the physical dimension, can be broken down into sub-dimensions such as physical fitness, the strength of muscles, and their ability to achieve their daily living events. Secondly, the emotional dimension, too, can be broken down into how an individual feels, their level of satisfaction towards family, friends, and everyday life events. The social dimension comprises features of communication, shared responsibilities, friendship, and a feeling of acceptance. The intellectual dimensions featured the capability of the information process, making clear values and beliefs and application of decision making. The fifth dimension, which is the spiritual dimensions, included faith, religion, beliefs, the comprehension of the importance of life. The last dimension is the environmental dimension on wellbeing, cleanness of the surrounding, access to healthcare, care, and financial resources (Nilvarangkul et al., 2010). All these dimensions were correlated against the demographic variables of the respondents, as advocated by Ferrans (1996). The demographic variables were age, education level, previous employment, and marital status.

Another scholar proposed that an elderly standard level of expectations for a decent life (QOL) is separated into three (3) dimensions. The first in dimensions named biological, which comprised of; health, knowledge on personal care, nonexistence for sickness or ache, and the capability of a person to travel from place to place. Secondly, is the psychological dimension. This dimension is comprised of; one's contentment, learning capacity, and capacity to perform exciting kinds of stuff. The last dimensions for elderly QOL are the social dimension. This social dimension includes; lively social interactions, helpful with other individuals, gaining social assistance when required, and be assisted by family or next of kin (Raphael, Waalen, \& Karabanow, 2001).

Besides that, the standard level of expectations for a decent life (QOL) is also understood as the association of goodness in life that corresponds to a person on how they look at the perspective in terms of psychological, biological, sociocultural, spiritual, and lastly environmental well-being. This is also in compliance with Kahlbaugh and Huffman (2017), whereas the individual's wellbeing will also exert influence by factors suchlike spiritual, sociological, psychological, and environmental. As it is, Hudson (2019) proposed a viewpoint of human welfare as an individual likes a significant potential that occurs in their life on the satisfaction that they are experiencing, pleasure in life, the ownership, or fulfillment of something. 
Many research projects on human wellbeing (QOL) were seen at aiming towards the physical dimensions or also known as external dimensions such as health, social, and their income (Çinarli \& Koç, 2017). Meanwhile, the subjective dimension is receiving fewer studies that comprised of the human experience, feelings, perception, and thought since the area is difficult to measure. Also, the elderly's well-being is affected by external surroundings such as parks and other recreational places (Pratiwi \& Furuya, 2019). Moreover, on the report of Kahlbaugh and Huffman (2017), a person's insight on their standard level of expectations for a decent life can be distinguished into various aspects, such as physical state, mental and spiritual state, state of individuality (independent), interactions with other individuals and their social connection. As noted by Raphael et al. (2001), previous studies were also indicated a similar definition for quality of life, whereas it understands as the virtue of life that was linked with perceived psychological, sociological, spiritual and environmental.

As indicated by Peng and She (2018), delineating the wellbeing factors for the individual and society's quality of life is broad. However, the measurement can occur crossways with other domains, albeit unclear or unfixed domain boundaries. Subsequently, this indicated that the individual or society's wellbeing might be interpreted differently; hence it varies on the topic of individual expectations of standard for a decent life. Since there are multivariates for the QOL, the focus is on socio-demographic variables as there was limited literature on the elderly's quality of life (QOL) in a geriatric care facility.

According to Seth, Yadav, Adichwal, and Kamble (2019), an individual's life quality was associated with the onset of sociodemographic variables, namely the length of time a person lives (age), relationship status, educational attainment and amount of income. For instance, Baraković Husić, Baraković, and Cero Dinarević (2020) provided factors of socio-demographic for the quality of life, which were; age, educational level, employment status, marital status, permanent place of living, the number of children, and self-assessment on financial and an individual living condition.

For the socio-demographic factors, it can be measured through the application of the QOL domains that were established by previous researchers (Ferrans, 1996). Thus, the socio-demographic factors can be measured by applying the questionnaire entitled Quality of Life Index (QLI) - Nursing Home III Version (ibid). Through the application of Ferrans and Powers QLI (ibid), an individual standard level of expectations for a decent life (QOL) was consistent with that of the dependent variable. As opined by Ohashi and Katsura (2019), the quality of life for senior citizens was associated with an individual's characteristics, happiness, and the aging process, which were all concerned with the interaction of social, economic factors, and cultural settings (ibid).

Moreover, as stated by Daskalopoulou et al. (2019), the majority of the elderly considered that good health would lead to a decent quality of life. However, others perceived that financial stability is more important than other factors. As a result, different perspectives restricted choosing the best and accurate instrument to measure the quality of life.

\subsection{Methodology}

As the study focused on the outcome or the quality of life among the elderly, the socio-demographic or independent variables consisted of age, level of education, prior employment, and relationship status. For this study, the theoretical underpinning is the Ferrans (1996) Conceptual Model to determine the relationship of demographic variables with that of the elderly's quality of life.

This study will be a cross-sectional survey through the application of a questionnaire to know the influence of selected sociodemographic features (age, education attainment, prior employment, and relationship status) against the wellbeing of a senior citizen who resides in a government welfare institution. A detailed investigation and analysis of elderly wellbeing took place in the golden-agers' welfare organization, Rumah Seri Kenangan Cheras, Selangor. Since the study will be using the quantitative method, a set of questionnaires that contains the Likert Scale, and it has the same question, will be used to avoid bias in the data collection.

The population for this study is the elderly in the Rumah Seri Kenangan (RSK) Cheras, Selangor. The information regarding the elderly in the RSK Cheras will be collected from the personnel in charge. One hundred forty-five senior citizens are living in the institution. For this research, a population sampling technique of all the 145 senior citizens will become respondents to representing the population.

\subsection{Findings}

From the analyses of the demographic variables, the profiles of the respondents are shown in Table 1. The main purpose of outlining the profile of respondents was to show the distribution for each demographic's characteristics of the elderly respondents. Among the characteristics that were taken into consideration were gender, age, ethnicity, religion, marital status, level of education, prior employment, and the number of children of the respondents at Rumah Seri Kenangan, Cheras, Kuala Lumpur, Malaysia.

To summarize Table 1 for each variable, starting with gender. As can be seen, male residents outnumber female ones by $58.6 \%$. Next, the age and ethnicity; $35.2 \%$ of residents are between 60 to 65 years of age, with Malay residents making the highest number at $57.2 \%$. In terms of religion and marital status; those from the Islamic faith have the highest score at $62.1 \%$, with $21.4 \%$ stating that they are married. For the level of education, $40 \%$ of the residents only studied up to primary school, with $48.5 \%$ of them who have worked in the private sector. Lastly, $49.7 \%$ of the respondents have no children. From the demographics' findings, the justifications for the elderly residents staying at this geriatrics care facility were validated, especially with the high percentage (49.7\%) of them not having children to care for them in their twilight years.

The discussions and implications for the demographic findings will be elaborated in the following section. 


\begin{tabular}{|c|c|c|c|}
\hline & & Frequency & Percentage \\
\hline \multirow[t]{2}{*}{ Gender } & Male & 85 & 58.6 \\
\hline & Female & 60 & 41.4 \\
\hline \multirow[t]{4}{*}{ Age } & $60-65$ years & 51 & 35.2 \\
\hline & $66-67$ & 19 & 13.1 \\
\hline & $68-69$ & 26 & 17.9 \\
\hline & 70 years and above & 42 & 29.0 \\
\hline \multirow[t]{4}{*}{ Ethnicity } & Malay & 83 & 57.2 \\
\hline & Chinese & 35 & 24.1 \\
\hline & Indian & 21 & 14.5 \\
\hline & Others & 6 & 4.1 \\
\hline \multirow[t]{6}{*}{ Religion } & Islam & 90 & 62.1 \\
\hline & Christian & 18 & 12.4 \\
\hline & Buddha & 19 & 13.1 \\
\hline & Hindu & 13 & 9.0 \\
\hline & Others & 1 & 0.7 \\
\hline & No religion & 4 & 2.8 \\
\hline \multirow[t]{3}{*}{ Marital Status } & Married & 31 & 21.4 \\
\hline & Separated & 6 & 4.1 \\
\hline & Divorced & 21 & 14.5 \\
\hline \multirow[t]{4}{*}{ Level of Education } & Primary & 38 & 40.0 \\
\hline & Lower Secondary (PT3) & 30 & 20.7 \\
\hline & Upper Secondary (SPM) & 13 & 9.0 \\
\hline & Higher Certificate (STPM) & 7 & 4.8 \\
\hline \multirow[t]{4}{*}{ Prior Employment } & Public Sector & 19 & 13.9 \\
\hline & Private Sector & 66 & 48.5 \\
\hline & Self Employed & 38 & 27.9 \\
\hline & Unemployed & 13 & 9.6 \\
\hline \multirow[t]{5}{*}{ Number of Children } & None & 72 & 49.7 \\
\hline & $1-2$ & 39 & 26.9 \\
\hline & $3-4$ & 23 & 15.9 \\
\hline & 5 & 1 & 7.0 \\
\hline & Above five children & 10 & 6.9 \\
\hline
\end{tabular}

The rest of the findings are highlighted per the research objectives from the relationship between four independent variables (age, education level, previous employment, marital status, and gender) and one dependent variable (quality of life).

Table 2. Results of Analyses

\begin{tabular}{cccc}
\hline Independent Variable & Chi-Square & P-value $(p<0.05)$ & Crammer's V \\
\hline Age & & & \\
Education Level & 5.509 & 0.702 & 0.138 \\
Previous Employment & 6.527 & 0.588 & 0.150 \\
Marital Status & 13.289 & 0.102 & 0.214 \\
\hline
\end{tabular}

The Chi-square analysis for Table 2 shows that the quality of life for the four age ranges identified have no significant relationship, that is, age is not a factor in enjoying what is left of their life.

The same results were interpreted for the education level of the elderly at RSKC, as shown from the $p$-value of 0.588 , previous employment ( $p=0.102)$, and marital status $(p=0.038)$ (see Table 2 ).

For the Levene's test between the quality of life and gender (Table 3), the findings indicated that gender does not affect the quality of life of the residents at RSK Cheras.

Table 3. Analysis between Quality of Life and Gender

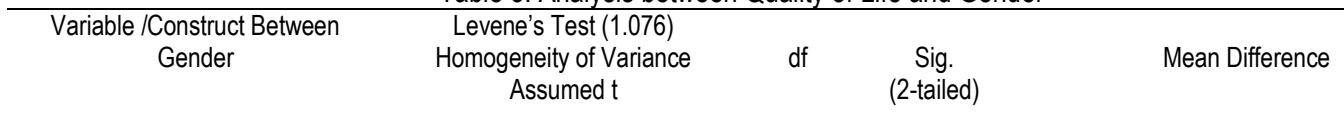

\begin{tabular}{|c|c|c|c|c|}
\hline $\begin{array}{l}\text { The level quality of life among } \\
\text { the elderly between Gender in } \\
\text { RSK Cheras }\end{array}$ & 1.076 & 98.707 & 0.285 & 0.10349 \\
\hline
\end{tabular}




\subsection{Discussions}

This study provided empirical evidence for insights into the wellbeing or quality of life of the residents at Rumah Seri Kenangan, Cheras, by analyzing the socio-demographic determinants; the length of time a person has lived (age), education attainment, prior employment, as well as the marriage status.

Correspondingly, this study has only found that based on four (4) selected socio-demographic factors. Only marital status showed a substantial connection with senior citizen's wellbeing in Rumah Seri Kenangan, Cheras. On the other hand, the level of quality of life among the elderly at Rumah Seri Kenangan also shown that there is a significant difference. Hence, this study will benefit the Malaysian Department of Social Welfare in gaining insight on the current quality of life among the elderly in Rumah Seri Kenangan. For instance, this study found that marital status has a significant relationship with the elderly wellbeing, Department of Social Welfare is hoped to take the initiative by proposing a long-standing recommendation in policies planning that can refine and promote quality of life.

Another implication derived from this study is the contribution to the literature on the aging population in Asia. It is hoped, from this study, it will invite other researchers to cultivate a detailed investigation on the general wellbeing of an individual (QOL), in the direction of the relationship and its determinant to create a better future for the elderly's welfare. With new findings, it is hoped that the government agencies, the Malaysian Department of Social Welfare, can put more exposure to the welfare of the elderly towards the public.

This exposure towards the elderly community will perhaps give some sense to the children in appreciating their parents better. The elderly need extra care as they are exposed to chronic diseases, the discrepancy in their financial status, and other detrimental issues. Geriatric wellbeing is affected by the marital status of the elderly and the likelihood of emotional distress among the elderly.

In Rumah Seri Kenangan, the elderly residents have leisure times that can be utilized by the welfare institution to organize a cheerful visitation as mostly done by local schools and universities. The lack of activities can lead to boredom and loneliness as the majority of the elderly are not visiting by their children. In some cases, the elderly also did not have their heir, hence putting them into the risk of emotional disturbance.

\subsection{Conclusion and Recommendations}

In conclusion, only marital status was shown to significantly affect the elderly's quality of life at Rumah Seri Kenangan, Cheras (RSK). The remaining socio-demographic determinants of age, education level, and prior employment do not affect the elderly's wellbeing. Also, residents who are married tend to experience mutual decent social and physical support. The increase in their social interactions, having a positive outlook on life and, becoming actively involved in leisure activities added to a better quality of life. Gender is also not an issue, but the different sets of customs, norms, and cultural beliefs were perceived to impact individual general wellbeing. Therefore, a bundled effort from numerous stakeholders is required to create a standard level of expectation towards a decent life among the elderly.

\section{Acknowledgments}

The study was supported in part from the Fundamental Research Grant Scheme (FRGS 053/2017) awarded by the Ministry of Higher Education, Malaysia. The authors would also like to thank Universiti Teknologi MARA (UiTM) for the grant and research management assistance.

\section{References}

Baraković Husić, J., Baraković, S., \& Cero Dinarević, E. (2020). Smart aging: are we succeeding? Paper presented at the IFMBE Proceedings.

Cellucci, C., \& Di Sivo, M. (2020) Active City for Healthy Ageing and Anti-globesity. In: Vol. 966. Advances in Intelligent Systems and Computing (pp. 286-294).

Çinarli, T., \& Koç, Z. (2017). Fear and Risk of Falling, Activities of Daily Living, and Quality of Life: Assessment When Older Adults Receive Emergency Department Care. Nursing Research, 66(4), 330-335. doi:10.1097/NNR.0000000000000227

Daskalopoulou, C., Koukounari, A., Wu, Y. T., Terrera, G. M., Caballero, F. F., de la Fuente, J., . . Prina, M. (2019). Healthy aging trajectories and lifestyle behavior: the Mexican Health and Aging Study. Scientific Reports, 9(1). doi:10.1038/s41598-019-47238-w

Ferrans, C. E. (1996). Development of a conceptual model of quality of life. Scholarly inquiry for nursing practice, 10(3), 293-304. Retrieved from https://www.scopus.com/inward/record.uri?eid=2-s2.0-0030228571\&partnerlD=40\&md5=70b6d1795db4eeb678fae5bf16cd0076

Fung, J. C. (2020) Place Familiarity and Community Ageing-with-Place in Urban Neighbourhoods. In. Advances in 21st Century Human Settlements (pp. 129-151).

Hudson, B. (2019). Commissioning for change: A new model for commissioning adult social care in England. Critical Social Policy, 39(3), 413-433. doi:10.1177/0261018318818960

Kahlbaugh, P., \& Huffman, L. (2017). Personality, Emotional Qualities of Leisure, and Subjective Well-Being in the Elderly. The International Journal of Aging and Human Development, 85(2), 164-184. doi:10.1177/0091415016685329

Nelson, T. D. (2016). The Age of Ageism. Journal of Social Issues, 72(1), 191-198. doi:10.1111/josi.12162

Nilvarangkul, K., McCann, T. V., Rungreangkulkij, S., \& Wongprom, J. (2010). Enhancing a Health-Related Quality-of-Life Model for Laotian Migrant Workers in Thailand. Qualitative Health Research, 21(3), 312-323. doi:10.1177/1049732310376635 
Ohashi, J., \& Katsura, T. (2019). A coaching program to improve quality of life in older people in Japan: A randomised controlled trial. British Journal of Community Nursing, 24(7), 315-322. doi:10.12968/bjcn.2019.24.7.315

Organization, W. H. (2018). Aging and health. Retrieved from https://www.who.int/news-room/fact-sheets/detail/ageing-and-health

Peng, C., \& She, P. W. (2018). "RAISE CHILDREN TO FIGHT AGAINST AGING": THE DETERMINANTS OF ELDERLY WELLBEING IN TODAY'S CHINA. Singapore Economic Review. doi:10.1142/S0217590818420031

Pratiwi, P. I., \& Furuya, K. (2019). The neighborhood park preferences and its factors among elderly residents in Tokiwadaira, Japan. Asian Journal of Behavioural Studies, 4(16), 15. doi:http://dx.doi.org/10.21834/ajbes.v4i16.178

Raphael, D., Waalen, J., \& Karabanow, A. (2001). Factor Analytic Properties of the Quality of Life Profile: Examination of the Nine Subdomain Quality of Life Model. Psychological Reports, 88(1), 265-276. doi:10.2466/pr0.2001.88.1.265

Seth, N., Yadav, A., Adichwal, N. K., \& Kamble, S. B. (2019). Elder abuse and its association with socio-demographic variables in India. Clinical Epidemiology and Global Health, 7(2), 188-191. doi:10.1016/j.cegh.2018.05.002

Statistics-Malaysia, D. o. (2019). Current Population Estimates, Malaysia, 2018-2019. Retrieved from

https://www.dosm.gov.my/v1/index.php?r=column/cthemeByCat\&cat=155\&bul_id=aWJZRkJ4UEdKcUZpT2tVT090Snpydz09\&menu_id=L0pheU43NWJwRWVSZkIWdz Q4TIhUUT09

Tobi, S. U. M., Fathi, M. S., \& Amaratunga, D. (2017). Ageing in Place, an Overview for the Elderly in Malaysia. In F. A. A. Nifa, C. K. Lin, \& A. Hussain (Eds.), 2nd International Conference on Applied Science and Technology 2017 (Vol. 1891). 